\title{
Research on the Management Path of Network Public Opinion Crisis in Universities under the Background of "Micro-era"
}

\author{
Min Luo, Yiqun Wang and Chanti Wu* \\ (Ningbo Dahongying University, Ningbo, Zhejiang 315175) \\ ${ }^{*}$ Corresponding author
}

\begin{abstract}
Keywords: Network Public Opinion in Colleges and Universities; Dissemination Characteristics; Management Path
\end{abstract}

\begin{abstract}
After entering the era of new media, all kinds of crises that use the Internet as a carrier have frequently occurred. As a part of social public crisis management, the management of network public opinion crisis in colleges and universities is of great significance to the development of colleges and universities. This paper takes the new media as the research perspective, analyzes the problems existing in the management of crisis public relations in colleges and universities and proposes the strategies before, during and after the crisis according to the principles of the corresponding public relations crisis management.

At present, We Media, represented by Microblog and WeChat, have become the most active players in the network and the emerging public opinion field. Faced with the era of We Media in which "everyone is a news communicator", the situation of network public opinion crisis management in colleges and universities has become more and more severe. Some unexpected incidents that have broken out in colleges and universities, if cannot be dealt with in a timely and effective manner, go through the network platform. Fermentation is likely to result in the crisis of network public opinion in colleges and universities, affecting the normal teaching order in colleges and universities, and adversely influencing internal stability and social image of colleges and universities. Therefore, in the "micro-era", how to make efforts to improve the university's ability to cope with the crisis and to minimize the losses and hazards caused by the crisis become the practical problems that adminstrators of colleges and universities must consider.
\end{abstract}

\section{Characteristics of New Media in the Spread of Network Public Opinion Crisis Events in Colleges and Universities}

The We Media platforms such as Microblog and WeChat have developed strong momentum due to their popularity, individuation, low threshold, and simple operation, and have caused traditional media to be challenged by We Media. It is precisely because of these new characteristics of the media that the network public opinion in the era of the media has exhibited the following characteristics.

The Grassroots Nature of the Dissemination of the Subject Makes it Difficult to Find the Source of Crisis Events

Compared with traditional media, the threshold of new media is relatively low and the operation is very simple. No matter who is on the Internet, computers, mobile phones, and other terminals can express their opinions online, share their feelings, express their emotions, and interact instantly with users in the north and south. Such a convenient way for information dissemination of mobile terminals makes new media more attractive, and more importantly, it allows many ordinary people to have the right to speak on the Internet. It is precisely because of this widespread participation in the popularization that the quality of the disseminators varies greatly, which has become an unavoidable issue in the new media era. Under such circumstances, Microblog and WeChat are often the main media for the transmission of crisis events in colleges and universities. Due to the hidden nature of the dissemination of the subjects, it is necessary to find a source that is comparable to a "needle in the haystack" and the disappearance of the "gatekeeper" role in the web2.0 era. While providing discourse space for the people, it has also become a breeding ground for rumors. If someone spreads rumors in the event of a crisis, it will be harder to find the "source" of crisis events. 
In the era of Web3.0, the creation of a personal portal allows users to build their own community network and personalized information platform, so that they are the masters for their own places, so that the network can better demonstrate the users' personality and people can be independent controlling the dissemination and sharing of information on the Internet. As a result, network public opinion is no longer dominated by a few opinion leaders, realizing a truly democratic and equal status, making the Internet more autonomous in its dissemination, spreading the news more quickly and making the target audience more accurate.

Autonomy and Interactivity of Dissemination Content Makes it Difficult to Figure out the Crisis Event

Anyone can express and create their own opinions through Microblog; participate in topic discussions based on their own values and interests, and forward and comment on other people's viewpoints to form self media with personal style. Microblog does not require splendid language and rigorous logic. As long as the content is appealing enough, it will gather the attention of netizens and quickly make the topic a hot topic or public opinion the focus. This also makes it difficult for people to verify the authenticity of information when sending information and the subjective factors of the disseminating subject may affect the objectivity and accuracy of the information. If adminstrators of colleges and universities do not release authoritative information through official channels at the first time of crisis, they are likely to lose their right to speak. And they may be used by speculators who are not sure about the truth or even have ulterior motives. Crisis information that is reproduced or disseminated through new media can be used. It may be distorted and even lead to an escalation of the crisis

\section{Immediacy of Dissemination Time and Space Enables Crisis Events Spread Rapidly}

The dissemination of Microblog is characterized by immediacy. As a new media dissemination tool, it is fast, convenient and time-sensitive. It can spread quickly in any time and space and the effect of transmission is significant. The speed of new media's immediacy and multimedia manifestation has surpassed that of a single traditional media and won the commanding heights of information dissemination. In particular, the combination of Microblog and mobile phones and other mobile terminals, combined with the shortness of the content and the convenience of the terminal, has opened up the restrictions of the fixed Internet and mobile Internet, so people can publish and receive information freely, which makes the crisis information in the university spread on the Internet within a short period of time and shortens the time for adminstrators of colleges and universities to cope with the crisis, and has made it more difficult to handle and even undergone qualitative changes.

\section{Fission-based Multi-center Dissemination Model Makes Crisis Events more Complicated}

In the era of new media, the one-to-many information dissemination model of traditional media has been broken, and a multi-center, many-to-many interactive network fission dissemination model has emerged. Individuals are network nodes, and the multi-level and fission dissemination of information is achieved through the docking with friends circles so as to achieve the spread of content, scope, depth, breadth and effectiveness of the geometric expansion. Some scholars have summarized the characteristics of crisis dissemination in the Microblog environment as the following: the release of negative information is more immediate and convenient, which leads to crisis quickly; the cohesion of negative information is stronger and the crisis is spreading faster, and the new negative news is derived and the crisis continues to escalate. Therefore, Microblog will make the complicated crisis events in colleges and universities more difficult in the dissemination process of crisis events in colleges and universities.

\section{Management Path of Network Crisis in Colleges and Universities in the New Media Era}

Steven Fink, a world-renowned crisis management expert, has divided the development of crisis events into four stages: The first stage is the incubation period of the crisis. The entire stage is the easiest period for dealing with the crisis, but it is the least likely to be known. The second stage is the period of crisis outbreak. This is the period with the shortest time, but the longest feeling in the four stages and it has the most serious psychological impact on people. The third stage is the period 
of crisis dissemination. This is the longest of the four stages, but if the crisis management is effective, it will be greatly shortened. The fourth stage is the crisis recovery stage. At this point, the organization is freed from the effects of the crisis, but it still needs to be vigilant and the crisis is still likely to return. Steven Fink's theory of crisis stage analysis also applies to the different stages of the network public opinion in colleges and universities under the current background of "micro-era". Based on the crisis stage analysis theory, the author analyzes coping strategies from three different stages: before-crisis (crisis incubation), during-crisis (outbreak and spread) and after-crisis (crisis recovery).

\section{Before Crisis: Launch Normal Public Relations to Cope with New Media}

Establish Public Relations Awareness in Response to New Media. New media is a double-edged sword. It has brought challenges to the management of crisis public relations in the new era, but it also provides us with unprecedented opportunities. Its influence in the process of social development should not be underestimated. Facing the power of the new media will help improve our ability to deal with it. In the past, the concept of media response needs to be changed. It is necessary to give full play to the main role of new media in crisis management, change the previous model of one-way response to traditional media, actively interact with new media, engage in equal dialogue, turn the past "overlook" into "horizontal look" and change the status of passive defense. "The best defense is offense" and active response and taking the initiative can avoid passive restraints.

Set up a New Media Emergency Plan. First, set up a crisis public relations emergency team composed of public relations personnel who are relatively familiar with the new media and are familiar with the law of network public opinion dissemination and development to deal with media relations during the crisis. Second, establish a crisis information management system. With campus LANs, Post Bars, forums and various government information disclosure platforms, and even teacher-student personal micro-blogs and Wechat, they can keep track of public opinions, discover hidden dangers in a timely manner and establish a sound information collection, reporting and publication system.

Use Internet Media for Public Opinion Monitoring and Dynamic Tracking. On the one hand, it is possible to use public opinion monitoring software to monitor specific words and sensitive words on the Internet 24 hours a day and to keep abreast of the dynamic changes in network public opinion. On the other hand, a network public opinion monitor system will be established to collect, feed back, and find information on topics inside and outside colleges and universities as well as topics that teachers and students are concerned about. Pay attention to the dynamic tracking of public opinion, keep abreast of social dynamics, pay close attention to websites and forums frequently visited by teachers and students, or campus microblogs, QQ groups, etc. to understand the issues teachers and students are concerned about, grasp their ideological trends and take timely response measures so as to take the initiative to resolve contradictions and eliminate the crisis.

Establish Information Disclosure and Press Spokesman System. Colleges and universities should take preventive measures and establish a sound work system for information disclosure before the outbreak of a crisis event. The information disclosure mechanism that is led by the principal, implemented and promoted by the various functional departments of the school and actively participated by teachers and students shall be perfected. Besides, the university news system of release and news spokespersons shall be improved to strengthen the initiative and authority of information disclosure in colleges and universities. It is necessary to establish a mechanism for disclosure of information of decision-making for major events to disclose information and the dynamic information in implementation on major issues involving the vital interests of teachers and students in schools prior to decision-making to avoid the crisis caused by the teachers' and students' unawareness of the truth.

\section{During Crisis: Launch Crisis Public Relations to Cope with New Media}

In general, after the outbreak of a crisis, it is necessary to formulate relevant coping strategies promptly and in a timely manner. Colleges and universities should follow the " 24 -hour rule of gold" to initiate public relations in the shortest time. 
Respond Quickly and Start Emergency Plan at the First Time. "Speed first" is one of the important principles of the "5S principle" of crisis public relations. If colleges and universities do not take the initiative in the dissemination of information, they are vulnerable to being passive. Therefore, colleges and universities must start new media emergency plan at the first time after the crisis breaks out and set up a new media emergency team to investigate the ins and outs of crisis events, formulate emergency plans in time, grasp the trend of network public opinion, and try to control crisis events in an operable range.

Seize the Initiative and Release Authoritative Information at the First Time. Public relation s expert Parkinson believes that the information vacuum caused by miscommunication in network crisis events will soon be dominated by unreal rumors. If colleges and universities do not let the public know the truth of the incident at the first time, they may be occupied by rumors and make the problem more complicated. From the perspective of communication science, the audience's memory of the first information is more profound and lasting than the information received afterwards, which is what people call "preemptive". The attitudes and positions displayed by colleges and universities at the first time will, to a large extent, affect the views of the public and public opinions on colleges and universities. If this opportunity is lost, colleges and universities will have to pay even higher price if they want to guide or reshape public opinions. Therefore, in the crisis event of colleges and universities, it is necessary to proactively release the authoritative information to provide crisis reports to the traditional media and new media and answer the public's doubts in a timely manner.

Designate a Special Press Spokesman. When crisis events occur in colleges and universities, the relevant departments of the school may be asked about the dynamics and progress of the incident. A dedicated press spokesman can effectively play the role of accurate and authoritative information dissemination so as to quickly stabilize the spread of the crisis. One of the important tasks of press spokesman in colleges and universities is to coordinate the uniform news caliber of various departments in the event of a crisis so as to avoid confusion. During this period, it is necessary to continue to communicate with different agencies to ensure consistency with the information rations issued by various functional departments of the university. As a result, it is vital to pay attention to the collection of network public opinion, always focus on the trend of networkt public opinion and grasp the public psychology, understand the direction of the public opinion to provide a reference for the colleges and universities to develop crisis management measures in a timely manner.

In the new media environment, when incidents occur, there are many channels for audiences to obtain information, but they cannot effectively identify their authenticity. The spokesman is to deliver the correct information in a timely, accurate and professional manner to reduce the occurrence and spread of rumors, appease the doubts, dissatisfaction, and even panic of school teachers and students, eliminate misunderstandings from the outside world and become a hub for information communication inside and outside the school.

Guide Public Opinion Together with Opinion Leaders. Opinion leaders are the "activists" in network communication. They are the first or most contacted mass media information in the crowd, and they disseminate their own reprocessed information to other people. They have the ability to influence others' attitudes. They are involved in mass communication, which will accelerate the speed of spread and increase the impact. In some crisis events, Internet users are often vulnerable to the opinions of opinion leaders in situations where the truth is unknown and the mainstream media are aphasia. Opinion leaders can decide or even change the direction of public opinion, so their role in crisis public relations and public opinion guidance cannot be ignored. In the era of new media, colleges and universities must attach importance to the communication and exchanges with opinion leaders, especially after the occurrence of crisis events, actively play the role of opinion leaders and firmly grasp this position. Experts or relevant personnel of colleges and universities or network forum moderators, Microblog V, opinion leaders of teachers and students, etc. can be invited to publish authoritative information through online media, promptly refute, and guide the public opinion through the interaction with them. Mainstream online media in colleges and universities, 
such as school post bars, official microblogs, and official WeChat platforms, are actively conducting accurate public opinion guidance and grasping the dominant power of public opinion dissemination.

Be Brave Enough to Take Responsibilities and Promptly Announce the Results. When the crisis breaks out, the reputation of colleges and universities will be questioned. At this time, colleges and universities should not shy away from the problem, shirking their responsibilities or flashing their words, but should stand up courageously to explain the antecedents and consequences of the crisis to the public. If a crisis event is indeed a mistake in colleges or universities, they should be brave enough to take responsibility and announce the disposal plan.

\section{After Crisis: Reshape Image of Colleges and Universities}

The end of the crisis does not mean the end of crisis management. The strategy of crisis management in colleges and universities should be changed accordingly, and the focus should be shifted to the issue of restoring the image of universities. In this stage, the confidence of the adminstrators of colleges and universities in crisis management should be restored; the aftereffects brought by the crisis should be reduced; the image of colleges and universities should be restored, and all work should be conducted in a normal and orderly manner.

Carry out Post-crisis Psychological Reconstruction and Demonstrate a "People-oriented" Image of Colleges and Universities. After the crisis is over, colleges and universities can actively carry out post-crisis psychological reconstruction through online media, demonstrate a "people-oriented" image of colleges and universities, and provide follow-up counseling on the psychological trauma of teachers and students in the crisis. Colleges and universities should actively use the online media's Microblog, WeChat, Post Bar and other tools to conduct psychological counseling for teachers and students, soothe their emotions and reduce the social shock caused by the crisis

Develop a Crisis Assessment Accountability Mechanism to Demonstrate a "Responsible" Image of Colleges and Universities. For administrators of colleges and universities, each crisis event is a process of learning and experience accumulation. Crisis events are not terrible. It is awful that they cannot draw lessons from the process of crisis management, face up to the lack of response measures and correct and improve the defects of the existing management systems and models timely. Therefore, after the crisis has subsided, administrators of colleges and universities should conduct a comprehensive summary and analysis of crisis events, carry out responsibility investigations for relevant responsible departments and responsible persons and eliminate the hidden dangers of similar crises from their internal root causes.

Establish a learning mechanism after the crisis, and through the evaluation and analysis of crisis events, summarize how to effectively handle crisis events in the era of new media and draw lessons to provide reference for future responses to new crises.

\section{Acknowledgement}

[Funds]: Zhejiang Provincial Social Sciences Research Group's key research topic: Research on the Management Mechanism of Network Public Opinion Crisis in Universities in Zhejiang Province under the Background of "Micro-era", Phased Achievements (Topic ID: 2016N13Z).

\section{References}

[1] Peng L, Xiaoping Z. Social Stratification and Cooperative Behavior in Spatial Prisoners' Dilemma Games [J]. PLOS ONE, 2015, 10(7): e0131005.

[2] Qingjun Wang, Yibo Li and Xueping Liu. Analysis of Feature Fatigue EEG Signals Based on Wavelet Entropy[J]. International Journal of Pattern Recognition and Artificial Intelligence, 2018, 32(8):1854023

[3] N. Prieto, B. Uttaro, C. Mapiye, T.D. Turner, M.E.R. Dugan, V. Zamora, M. Young, E. Beltranena: Meat Science, Vol. 98 (2014) No.4, p.585.

[4] R. Riovanto, M. De Marchi, M. Cassandro and M. Penasa: Food Chemistry, Vol. 134 (2012) No.4, p. 2459. 
[5] N. Prieto, M.E.R. Dugan, O. López-Campos, T.A. McAllister, J.L. Aalhus and B. Uttaro: Meat Science, Vol. 90 (2012) No.1, p.43.

[6] N. Prieto, ó. López-Campos, J.L. Aalhus, M.E.R. Dugan, M. Juárez and B. Uttaro: Meat Science, Vol. 98 (2014) No.2, p.279.

[7] M. Pla, P. Hernández, B. Ari?o, J.A. Ramírez and Isabel Díaz: Food Chemistry, Vol. 100 (2007) No.1, p.165.

[8] R.R. Pullanagari, I.J. Yule and M. Agnew: Meat Science, Vol. 100 (2015), p.156.

[9] Saudland, A., Wagner, J., Nielsen, J. P., Munck, L., N?rgaard, L. and Engelsen, S. B: Applied Spectroscopy, Vol. 54 (2000) No.3, p.413.

[10] Balabin, R. M. and Smirnov, S. V: Analytica Chimica Acta, Vol. 692 (2011) No.1-2, p.63. 